American Journal of Life Sciences
2015;3(1): $27-31$
Published online January 31, 2015 (http://www.sciencepublishinggroup.com/j/ajls)
doi: $10.11648 /$ jajls.20150301.16
ISSN: 2328-5702 (Print); ISSN: $2328-5737$ (Online)

\title{
Nkombo Island: The most important Schistosomiasis mansoni focus in Rwanda
}

\author{
Eugene Ruberanziza ${ }^{1,}$, , Michée Kabera ${ }^{1}$, Giuseppina Ortu ${ }^{2}$, Kirezi Kanobana ${ }^{3}$, Denise Mupfasoni ${ }^{1}$, \\ Josh Ruxin ${ }^{1}$, Alan Fenwick ${ }^{2}$, Thierry Nyatanyi ${ }^{4}$, Corine Karema ${ }^{4}$, Tharcisse Munyaneza, \\ Katja Polman ${ }^{3}$
}

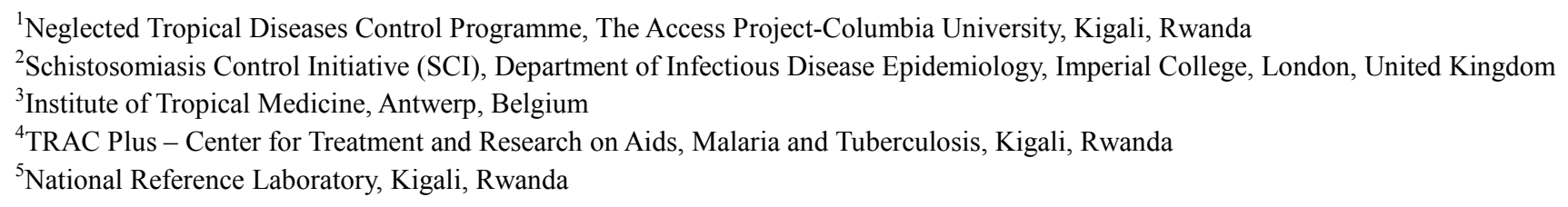

\section{Email address:}

ruberanzizaeugene@gmail.com (E. Ruberanziza)

\section{To cite this article:}

Eugene Ruberanziza, Michée Kabera, Giuseppina Ortu, Kirezi Kanobana, Denise Mupfasoni, Josh Ruxin, Alan Fenwick, Thierry Nyatanyi, Corine Karema, Tharcisse Munyaneza, Katja Polman. Nkombo Island: The Most Important Schistosomiasis mansoni Focus in Rwanda. American Journal of Life Sciences. Vol. 3, No. 1, 2015, pp. 27-31. doi: 10.11648/j.ajls.20150301.16

\begin{abstract}
In Rwanda, the initial school-based mapping of schistosomiasis and soil-transmitted helminth (STH) infections was completed in 2008. Despite the classification of low endemicity of intestinal schistosomiasis (Schistosoma mansoni) in Rusizi district, the Neglected Tropical Disease (NTD) programme has received warnings two years after the mapping on high infection level on Nkombo Island located in this district. This study aims to report on prevalence of Schistosoma mansoni infection in an area which was the last to be investigated in Rwanda and provide some critics on current mapping guidelines. The study was done in January 2011 with a sample of 311 schoolchildren aged 10-19 years. Stool screening was performed by Kato-Katz technique. Overall prevalence of $S$. mansoni was found to be $62.1 \%$ (95\%CI: 56.4-67.5), ranging from 28.6\% (95\%CI: 19.2-39.5) to $77.9 \%$ (95\%CI: $67.0-86.6)$ across the schools. The prevalence of $S$. mansoni among the schoolchildren of Nkombo Island was found to be the highest in Rwanda. These findings confirm the extreme focality of schistosomiasis and the fact that the current mapping guidelines are likely to miss some hotspots. For the validation of schistosomiasis distribution at country level, there is need for new innovative mapping methodology that can provide to control programmes more accurate data for planning and undertaking control interventions at the district and the lowest implementation levels. When mapping units have to be designed they should give more priority to areas surrounding perennial water bodies that are considered high-risk zones.
\end{abstract}

Keywords: Nkombo Island, Rwanda, S. mansoni, Schistosomiasis, STH, A. Lumbricoides, T. Trichiura, Hookworm, Prevalence, Intensity, Schoolchildren, Neglected Tropical Diseases

\section{Introduction}

In Rwanda, the Neglected Tropical Disease (NTD) control programme was established in 2007 with objective to decrease the morbidity due to seven NTDs (three soil-transmitted helminth (STH) infections: ascariasis, trichuriasis and hookworm; schistosomiasis, trachoma, lymphatic filariasis and onchocerciasis) to the levels where the diseases are not of public health significance. Many collaborating partners were engaged to support the Rwandan Ministry of Health. These included the Schistosomiasis Control Initiative (SCI), Geneva Global, Global Network for Neglected Tropical Diseases

(GNNTDC), Columbia University and Access Project [1]. Although this program was established to fight against seven NTDs, only schistosomiasis and STHs were found to constitute public health problems in Rwanda [2-3]. The first nationwide mapping completed in 2008 revealed that the prevalence of intestinal schistosomiasis (Schistosoma mansoni) was ranging from 0 to $69.5 \%$ across all surveyed schools while urinary schistosomiasis (Schistosoma haematobium) was not found $[3,4]$.

Until early 2011, the NTD control programme was 
smoothly implemented at national level and comprised mass drug administration (MDA) [1] for STHs in all districts of the country while MDA for schistosomiasis was restricted to areas where the mapping revealed a prevalence of at least $10 \%$ in randomly sampled schools. Adults from riverine villages were treated only if the prevalence exceeded 30\% according to National MDA Plan - adapted from WHO Guidelines [5]. The mapping was performed in accordance with the current guidelines of the World Health Organization (WHO) [6]. However, based on routine data, the NTD control programme has received some warnings on high infection level on Nkombo Island located in Rusizi district contradicting the classification of low endemicity of intestinal schistosomiasis by the aforementioned mapping. This study aims to provide decision-makers and scientists with reliable epidemiological data on intestinal schistosomiasis endemicity on Nkombo Island and a critical note about the current inadequate mapping procedures.

\section{Materials and Methods}

\subsection{Study Area and Participants}

Nkombo is the largest Rwandan island with a surface of 22 $\mathrm{km} 2$. It is seated on the Lake Kivu that stands $1463 \mathrm{~m}$ above sea level with a surface area of $2370 \mathrm{~km} 2$ [http://www.lakekivu.org/about_kivu]. The island is one of administrative sectors of Rusizi district. The latter is characterized by moderate tropical climate with average temperature varying between $20^{\circ}$ and $23^{\circ} \mathrm{C}$ and annual average rainfall of about $1450 \mathrm{~mm}$. The population of Nkombo is estimated at 16,000 inhabitants [www.rusizi.gov.rw], distributed in one large and 2 small sub-islands. Nkombo has 4 primary schools and one secondary school. Despite the sterile soil which does not favor any food crop, subsistence farming is practiced by the majority of the population. The population uses the lake water for most their day-to-day activities (i.e. cooking, drinking, washing, bathing and swimming is frequently practiced by children as leisure). Fishing is commonly practiced by both adults and children.

Disregarding their age, all pupils who were attending classes 4, 5 and 6 in primary schools of Nkombo Island during the time of data collection in late January 2011 were eligible to participate in our study. Since 2008, the school children of Nkombo were given albendazole or mebendazole for STH control as part of the national MDA campaigns.

\subsection{Ethics Statement}

Although this study would not require institutional ethical clearance given the circumstances in which it has been conducted: emergency investigation and rapid interventions of the Ministry of Health, the NTD control programme has considered this study as an additional investigation to the nationwide mapping completed in 2008. The latter was approved by the Rwanda National Ethics Committee (RNEC) and the Institutional Review Board (IRB) of Columbia
University - New York. Permission to collect data was obtained from the school directors who informed teachers and parents on the importance of schistosomiasis screening among schoolchildren. Informed written consent from the parents/guardians and the assent from the participants were also obtained as a prerequisite.

\subsection{Sample Size and Sampling Procedures}

All 4 primary schools of Nkombo were included and it was estimated that a sample of 70 children from upper classes (4, 5 , and 6) in each school would be adequate [7]. The sampling frame was the lists of pupils for each upper class from which a systematic sampling allowed to select the equal number of boys and girls.

\subsection{Questionnaire}

Data on participants' identification including names, age, sex, class and school were collected using a paper-based questionnaire. These data were supplemented with the outcome parasitological evaluation. In addition, Global Positioning System (GPS) by the means of an HP ipaq Personal Digital Assistant (PDA) was used to record the geographical coordinates for each school.

\subsection{Procedures}

Four trained and experienced medical laboratory technicians with two of them having participated in the national mapping were recruited to perform microscopy using Kato-Katz technique [8]. The selected school children were supplied with labelled plastic containers with applicator sticks and waterproof papers and were instructed to bring proper stool samples (single sample for each schoolchild). All specimens were checked for correct labelling and quantity of sample. Two slides per stool specimen $(2 \times 41.7$ $\mathrm{mg}$ of faeces) were prepared and read by two microscopists.

\subsection{Quality Assurance}

The quality control was performed in the field by a senior laboratory technician from the National Reference Laboratory (NRL). Each day of the survey, at least $10 \%$ of samples of each microscopist were randomly picked and rechecked without prior knowledge of the results. A discrepancy of up to $10 \%$ for egg counts was considered as normal, but if the discrepancy was larger, the laboratory technician from NRL read the slides again for final result.

\subsection{Data Management and Statistical Analysis}

Double data entry and cross-checking was performed in Epi-Info 3.5.3 of 2011 (United States Centers for Disease Control and Prevention (CDC), Atlanta, GA) by the NTD control program staff under supervision of the programme data manager. Single identification was given for each participant to avoid double counting. For statistical analysis, we used Epi-Info Software, version 3.5.3. Prevalence and intensity [9] of infections were calculated, with the latter 
expressed as the arithmetic mean of egg counts ( EPG/n) including only cases (n). This was further categorized into three outcomes namely light infection, moderate infection and heavy infection as per WHO definition of intensity of infection. The prevalence of $S$. mansoni also considered low $(<10 \%)$, moderate $(\geq 10 \%$ but $<50 \%)$ and high $(\geq 50 \%) \quad[9$, $10]$.

\section{Findings}

\subsection{Demographic Data}

A total of 311 schoolchildren from the 4 primary schools of Nkombo Island namely Bugumira, Nkombo, Gihaya and Ishywa were screened. The proportion of boys and girls was similar with 155 boys (49.8\%) and 156 girls (50.2\%). Sex ratio was 0.99 . In all schools the age of the children ranged between 10 and 19 years. Overall mean age was $13.8(\mathrm{SD}=1.7)$ years with $14.2(\mathrm{SD}=1.9)$ years for Bugumira and 13.6 years for each of the remaining schools. Participants were distributed in schools as following: $84(27.0 \%), 81(26.0 \%)$, $77(24.8 \%)$ and $69(22.2 \%)$ children for Ishywa, Bugumira, Gihaya and Nkombo, respectively. (Table 1)

\subsection{Prevalence of Schistosomiasis Mansoni}

Overall S. mansoni infection was diagnosed in 193 schoolchildren giving a prevalence rate of $62.1 \%$ (95\% CI: 56.4-67.5). Boys were more infected than girls with a prevalence of $65.8 \%$ (95\% CI: 57.8-73.2) and 58.3\% (95\% CI: 50.2-66.2), respectively, but the difference was not statistically significant $(\mathrm{p}>0.05)$. At school level, the highest infection prevalence was found in Gihaya with $77.9 \%(95 \%$ CI: 67.0-86.6) followed by Bugumira with $72.8 \%$ (95\% CI: 61.8-82.1), Nkombo with 72.5\% (95\% CI: 60.4-82.5) whilst the prevalence was far lower in Ishywa with $28.6 \%$ (95\% CI: 19.2-39.5) (Table 2).

\subsection{Intensity of $S$. mansoni infection}

The faecal egg count (eggs per gram faeces (EPG)) ranged from 12 to 14400 and the overall average of positives was 176.9 EPG (number of infected individuals as denominator). The intensity was predominantly light with 137 individuals out of the $193(71.0 \%)$ having a light infection intensity. Moderate infection intensity accounted for 48 cases (24.9\%) while heavy infection intensity was relatively rare with only 8 cases $(4.1 \%)$ (Table 3$)$

\subsection{Prevalence and Intensity of STH Infections}

Overall, the proportion of children harboring at least one STH was $95.2 \%$ (95\% CI: 92.0-97.2), and the prevalence of individual STHs was $92.9 \%$ (95\% CI: 89.3-95.4), 35.7\% (95\% CI: 30.4-41.3) and 11.6\% (95\% CI: 8.3-15.8) for T. trichiura, A. lumbricoides and hookworm, respectively. The prevalence of infection with at least one STH was $96.1 \%$ (95\% CI: 89.0-99.2), 88.4\% (95\% CI: 78.4-94.9), 96.3\% (95\% CI: 89.6-99.2) and $98.8 \%$ (95\% CI: 93.5-100.0) in Gihaya, Nkombo, Bugumira and Ishywa, respectively (Table 2). STH infections were mainly of light intensity $(92.0 \%, 65.8 \%$ and $100.0 \%$ for $T$. trichiura, A. lumbricoides and hookworm infection, respectively). Moderate intensity was found in $34.2 \%$ and $8.0 \%$ of children for A. lumbricoides and $T$. trichiura, respectively. None of the STH infections were of heavy intensity (Table 3).

\section{Discussion}

The present study shows that $S$. mansoni infection is highly endemic on Nkombo Island with an overall prevalence of $62.1 \%$ in schoolchildren, ranging from $28.6 \%$ to $77.9 \%$ across the primary schools. Based on these results, this area ranks higher than other schistosomiasis foci so far investigated in Rwanda. Previous studies have reported moderate to high endemicity of $S$. mansoni around Lakes Ruhondo, Burera, Muhazi, Rweru and some sites of Lake Kivu - east shore [2, 3, 11-13]. The situation of intestinal schistosomiasis on Nkombo was unknown before the present data were collected, and this area was assumed to be a low prevalence zone based on the mapping results obtained from six schools randomly selected elsewhere in Rusizi district. With this context, it is clear that unbiased sample may not be optimally achieved using the current WHO guidelines that recommend random sampling of few schools based on ecological zones [8, 11] and consequently, omission of some high endemic communities that would be qualified for mass treatment. Several authors have described the small-scale focality of schistosomiasis [14-20].

With this update, the highest prevalence of $S$. mansoni infection in Rwanda is found on Nkombo Island. For the control of its related morbidity, mass distribution of praziquantel to school age children and adults should be implemented as per the current national MDA plan. In addition, supply of potable water, improved sanitation and health education should inevitably be planned to reduce the transmission of schistosomiasis on this island.

While accurate data are needed and an attempt for transmission control and schistosomiasis elimination is getting on the international public health agenda [21], there is extreme need for new innovative mapping methodology that takes account of the focality of schistosomiasis. This infection usually occurs within $5 \mathrm{~km}$ of perennial water bodies. Thus a high-risk $5 \mathrm{~km}$-buffer zone around these water bodies and the creation of mapping units to allow selection of schools in a good number where schistosomiasis is most likely to occur, are some of the recommendations that should be considered when elaborating new guidelines. 
Table 1. Demographic characteristics of participants.

\begin{tabular}{|c|c|c|c|c|c|}
\hline Characteristic & Bugumira & Nkombo & Gihaya & Ishywa & Total \\
\hline \multicolumn{6}{|l|}{ Age (years) } \\
\hline Mean (SD) & $14.2(1.9)$ & $13.6(1.8)$ & $13.6(1.8)$ & $13.6(1.4)$ & $13.8(1.7)$ \\
\hline \multicolumn{6}{|l|}{ Sex } \\
\hline Male (n, \%) & $42(51.9)$ & $36(52.2)$ & $35(45.5)$ & $42(50.0)$ & $155(49.8)$ \\
\hline Female (n, \%) & $39(48.1)$ & $33(47.8)$ & $42(54.5)$ & $42(50.0)$ & $156(50.2)$ \\
\hline
\end{tabular}

Table 2. Prevalence of S. mansoni and STHs among surveyed schoolchildren.

\begin{tabular}{|c|c|c|c|c|c|}
\hline \multirow[b]{2}{*}{ Characteristic } & \multicolumn{5}{|c|}{ Prevalence n (\%) [95\% CI] } \\
\hline & S. mansoni & T. trichiura & A. lumbricoides & Hookworm & Any STH \\
\hline Overall & 193 & 289 & 111 & 36 & 296 \\
\hline$(\mathrm{n}=311)$ & $62.1(56.4-67.5)$ & $92.9(89.3-95.4)$ & $35.7(30.4-41.3)$ & $11.6(8.3-15.8)$ & $95.2(92.0-97.2)$ \\
\hline \multicolumn{6}{|l|}{ Per school } \\
\hline \multirow{2}{*}{ Bugumira } & 59 & 76 & 23 & 3 & 78 \\
\hline & $72.8(61.8-82.1)$ & $93.8(86.2-98.0)$ & $28.4(18.9-39.5)$ & $3.7(0.8-10.4)$ & $96.3(89.6-99.2)$ \\
\hline \multirow{2}{*}{ Nkombo } & 50 & 59 & 28 & 6 & 61 \\
\hline & $72.5(60.4-82.5)$ & $85.5(75.0-92.8)$ & $40.6(28.9-53.1)$ & $8.7(3.3-18.0)$ & 88.4 (78.4-94.9) \\
\hline \multirow{2}{*}{ Gihaya } & 60 & 72 & 28 & 24 & 74 \\
\hline & $77.9(67.0-86.6)$ & $93.5(85.5-97.9)$ & $36.4(25.7-48.1)$ & $31.2(21.1-42.7)$ & $96.1(89.0-99.2)$ \\
\hline \multirow{2}{*}{ Ishywa } & 24 & 82 & 32 & 3 & 83 \\
\hline & $28.6(19.2-39.5)$ & $97.6(91.7-99.7)$ & $38.1(27.7-49.3)$ & $3.6(0.7-10.1)$ & $98.8(93.5-100.0)$ \\
\hline \multicolumn{6}{|l|}{ Per sex } \\
\hline \multirow{2}{*}{ Male } & 102 & 148 & 72 & 19 & 149 \\
\hline & $65.8(57.8-73.2)$ & $95.5(90.9-98.2)$ & $46.5(38.4-54.6)$ & $12.3(7.5-18.5)$ & 96.1 (91.8-98.6) \\
\hline \multirow{2}{*}{ Female } & 91 & 141 & 39 & 17 & 147 \\
\hline & $58.3(50.2-66.2)$ & $90.4(84.6-94.5)$ & $25(18.4-32.6)$ & $10.9(6.5-16.9)$ & $94.2(89.3-97.3)$ \\
\hline
\end{tabular}

Table 3. Intensity of S. mansoni and STHs.

\begin{tabular}{|c|c|c|c|c|}
\hline Intensity in infected individuals & $\begin{array}{l}\text { S. mansoni } \\
\mathrm{n}=193\end{array}$ & $\begin{array}{l}\text { T. trichiura } \\
\mathrm{n}=\mathbf{2 8 9}\end{array}$ & $\begin{array}{l}\text { A. lumbricoides } \\
\mathrm{n}=111\end{array}$ & $\begin{array}{l}\text { Hookworm } \\
\mathrm{n}=36\end{array}$ \\
\hline $\begin{array}{l}\text { Overall mean EPG } \\
\text { Intensity category }(n, \%)\end{array}$ & 177 & 389 & 4820 & 64 \\
\hline Light & $137(71.0)$ & $266(92.0)$ & $73(65.8)$ & $36(100.0)$ \\
\hline Moderate & $48(24.9)$ & $23(8.0)$ & $38(34.2)$ & none \\
\hline Heavy & $8(4.1)$ & none & none & none \\
\hline
\end{tabular}

\section{Acknowledgements}

The authors are grateful for the cooperation of the administration staffs of Gihundwe district hospital, the head staff of Nkombo health center, school teachers and participants as well as the laboratory technicians who participated in the data collection. Many thanks also are addressed to the head and senior staff of the National Reference Laboratory for their technical support. The NTD control programme was supported by the Government of Rwanda and the following donors: Legatum, Geneva Global (GG), Global Network for Neglected Tropical Diseases (GNNTDC) and Schistosomiasis Control Initiative (SCI).

\section{References}

[1] Ruxin J, Negin J. Removing the neglect from neglected tropical diseases: The Rwanda experience 2008-2010. Global Public Health 2012 Sep;7(8):812-822.

[2] Mupfasoni D, Karibushi B, Koukounari A, Ruberanziza E, Kaberuka T, Kramer MH, et al. Polyparasite helminth infections and their association to anaemia and undernutrition in Northern Rwanda. PLoS Negl Trop Dis 2009;3(9):e517.
[3] Ruberanziza E, Mupfasoni D, Karibushi B, Kabera M, Karema C, Nyatanyi T, Ruzindana E, Gatabazi JB, Mukabayire O, Fenwick A, Ruxin J. A recent update of schistosomiasis mansoni endemicity around Lake Rweru. Rwanda Medical Journal 2010 Dec;68(4):6-9.

[4] Clerinx J, Bottieau E, Wichmann D, Tannich E, Van Esbroeck M. Acute Schistosomiasis in a Cluster of Travelers From Rwanda: Diagnostic Contribution of Schistosome DNA Detection in Serum Compared to Parasitology and Serology. J. Travel Med 2011;18:367-372.

[5] World Health Organization (WHO). Preventive chemotherapy in human helminthiasis: coordinated use of anthelminthic drugs in control interventions : a manual for health professionals and program managers. World Health Organization. Geneva; 2006.

[6] Montresor A, Crompton DWT, Hall A, Bundy DAP, Savioli L. Guidelines for the evaluation of soil-transmitted helminthiasis and schistosomiasis at community level. Geneva; 1998. Report No.: WHO/CTD/SIP/98.1.

[7] Lwanga KS, Lemeshow S. Sample size determination in health studies. A practical manual. World Health Organization. Geneva; 1991.

[8] Katz N, Chaves A, Pellegrino J. A simple device for quantitative stool thick-smear technique in schistosomiasis mansoni. Rev Inst Med Trop S Paulo 1972;14: 397-400. 
[9] Montresor A, Crompton DW, Gyorkos TW and Savioli L. Helminth control in school age children. A Guide for Managers of Control Programmes. Geneva: World Health Organization. 2004.

[10] Steinmann P, Keiser J, Bos R, Tanner M, Utzinger J. Schistosomiasis and water resources development: systematic review, meta-analysis, and estimates of people at risk. Lancet Infect Dis 2006 Jul;6(7):411-25.

[11] Hanotier J, Gigase PL. Note on a new focus of schistosomiasis (S. mansoni) in Rwanda. Ann Soc Belg Med Trop 1981 Mar; 61(1): $93-8$

[12] Ruberanziza E, Gahimbare L, Musemakweri A, Vervoort T, Van den Ende J, Clerinx J. Schistosomiasis mansoni in children around Lake Ruhondo, Rwanda. A clinico-epidemiological study. RMJ 2007;66(2):5-11.

[13] Vimont Vicary MP. [Recent detection of a schistosomiasis focus with S. mansoni in a high region of Rwanda (author's transl)]. Med Trop (Mars ) 1981 Nov;41(6):653-6.

[14] Brooker S. Schistosomes, snails and satellites. Acta Trop 2002 May;82(2):207-14.

[15] Raso G, Matthys B, N'goran EK, Tanner M, Vounatsou P, Utzinger J. Spatial risk prediction and mapping of Schistosoma mansoni infections among schoolchildren living in western Cote d'Ivoire. Parasitology 2005 Jul;131(Pt 1):97-108.

[16] Raso G, Vounatsou P, Singer BH, N'goran EK, Tanner M, Utzinger J. An integrated approach for risk profiling and spatial prediction of Schistosoma mansoni-hookworm coinfection. Proc Natl Acad Sci U S A 2006 May 2;103(18):6934-9.

[17] Brooker S, Alexander N, Geiger S, Moyeed RA, Stander J, Fleming $\mathrm{F}$, et al. Contrasting patterns in the small-scale heterogeneity of human helminth infections in urban and rural environments in Brazil. Int J Parasitol 2006 Sep; 36(10-11): $1143-51$.

[18] Clements AC, Lwambo NJ, Blair L, Nyandindi U, Kaatano G, Kinung'hi S, et al. Bayesian spatial analysis and disease mapping: tools to enhance planning and implementation of a schistosomiasis control programme in Tanzania. Trop Med Int Health 2006 Apr;11(4):490-503.

[19] Simoonga C, Kazembe LN, Kristensen TK, Olsen A, Appleton CC, Mubita P, et al. The epidemiology and small-scale spatial heterogeneity of urinary schistosomiasis in Lusaka province, Zambia. Geospat Health 2008 Nov;3(1):57-67.

[20] Appleton CC. Review of literature on abiotic factors influencing the distribution and life-cycles of bilharziasis intermediate host snails. Malacol Rev 1978;11:1-25.

[21] Knopp S, Person B, Ame SM, Mohammed KA, Ali SM, Khamis S, et al. Elimination of Schistosomiasis Transmission in Zanzibar: Baseline Findings before the Onset of a Randomized Intervention Trial. Plos Negl Trop Dis 2013 Oct; 7(10):10.1371/annotation/d5135174-e4ff-44c6-9c04-17c072a 4 fd0b.

doi:10.1371/annotation/d5135174-e4ff-44c6-9c04-17c072a4fd $0 \mathrm{~b}$ 